\title{
Morfologia externa dos estágios imaturos de heliconíneos neotropicais. II. Dione juno juno (Cramer) (Lepidoptera, Nymphalidae, Heliconiinae) ${ }^{1}$
}

\author{
Maurício Tavares ${ }^{2}$ \\ Lucas A. Kaminski ${ }^{2}$ \\ Gilson R.P. Moreira ${ }^{2,3}$
}

\begin{abstract}
External morphology of the immature stages of neotropical heliconians. II. Dione juno juno (Cramer) (Lepidoptera, Nymphalidae, Heliconiinae). The external features of egg, larva and pupa of Dione juno juno (Cramer, 1779) are described and illustrated, based upon light and scanning electron microscopy.

KEY WORDS. Lepidoptera, Nymphalidae, Heliconiini, immature stages, morphology
\end{abstract}

Dione juno (Cramer, 1779) (Lepidoptera, Nymphalidae) distribui-se por toda América Central, grande parte da América do Sul e Antilhas Menores (EMSLEY 1963; DeVRIES 1987). Até o momento, foram reconhecidas cinco subespécies: Dione juno juno, Dione juno huascuma (Reakirt, 1866), Dione juno andicola (Bates, 1864), Dione juno suffumata Brown \& Mielke, 1972 e Dione juno miraculosa Hering, 1926 (EMSLEy 1963; BROWN \& MIELKE 1972; BROWN 1975). A primeira, objeto deste estudo, distribui-se amplamente na América do Sul e Antilhas Menores.

Dione juno é comumente encontrada em áreas abertas e ambientes perturbados, mas pode ocorrer em florestas primárias, no dossel (DEVRIES 1987). Alimenta-se, geralmente, em flores de coloração alaranjada e vermelha, das quais retira somente néctar (BROWN \& MielKe 1972; KRENN \& PENZ 1998). Em associação com outras borboletas da tribo Heliconiini, constitui o anel mimético mülleriano do grupo "laranja", do qual fazem parte ainda Dryas iulia (Fabricius, 1775), Eueides aliphera (Godart, 1819), Dione moneta Hübner, 1825 e Agraulis vanillae (Linnaeus, 1758) (G.L. Garcias, UFRGS, dados não publicados), dentre outras. As posturas, com número variável de 60 a 140 ovos (MUYSHONDT et al. 1973; BROWN 1981), são depositadas sob folhas de diversas espécies de Passiflora Linnaeus, pertencente principalmente ao subgênero Granadilla (Medic.) Masters. Utiliza-se também daquelas pertencentes a Distephana (Juss.) Killip e Plectostemma Masters (BENSON et al. 1976). As larvas possuem comportamento gregário e comumente são encontradas sobre Passiflora edulis Sims (MUYSHONDT et al. 1973), a qual é mundialmente utilizada em cultivos comer-

1) Contribuição número 379 do Departamento de Zoologia, Universidade Federal do Rio Grande do Sul.

2) Departamento de Zoologia, Instituto de Biociências, Universidade Federal do Rio Grande do Sul. Avenida Bento Gonçalves 9500, 91501-970 Porto Alegre, Rio Grande do Sul, Brasil.

3) E-mail: gilson.moreira@ufrgs.br 
ciais (VANDERPLANK 1991). Por provocarem severos desfolhamentos às plantas de $P$. edulis, constituem-se um problema agronômico, sendo a espécie considerada uma das principais pragas da cultura do maracujá (LARA et al. 1999).

Aspectos gerais referentes à morfologia dos estágios imaturos dos heliconíneos de Trinidad, incluindo $D$. juno, foram abordados por BEEBE et al. (1960) e FLEMING (1960). Significativos aportes à morfologia ultraestrutural dos imaturos de Heliconiinae têm sido obtidos recentemente, sendo sua importância reconhecida especialmente no que concerne a filogenia do grupo (PENZ 1999; ANTUNES et al. no prelo; KAMINSKI et al. 2002). Os estágios imaturos de $D$. juno não haviam sido contemplados neste contexto, o que é objetivo deste trabalho. Descreve-se e caracteriza-se os estágios imaturos de $D$. juno juno através da microscopia óptica e eletrônica de varredura, tendo como ênfase: ultraestrutura superficial do ovo, quetotaxia primária e secundária da larva, identificação morfométrica dos ínstares, morfologia externa geral e ultraestrutural da pupa.

\section{MATERIAL E MÉTODOS}

Ovos e pupas de $D$. juno juno foram coletados nos arredores de Porto Alegre, Rio Grande do Sul, sobre folhas de P. edulis Sims, sacrificados, fixados e preservados em fluido de Dietrich. De ovos adicionais coletados, foram criadas larvas para identificação dos ínstares e estudo da quetotaxia. As larvas eram mantidas sobre ramos de $P$. edulis distribuídos em garrafas plásticas contendo água e cobertos por tela de malha fina. Para a identificação dos ínstares ( $n=20$ larvas/ínstar) marcava-se, com tinta para tecido (Acrilex $\left.{ }^{(}\right)$, a extremidade posterior do abdômen das larvas, alterando as cores por ocasião das ecdises. As larvas eram observadas diariamente, quando eram substituídos os ramos, se necessário, bem como efetuada a reposição das marcas e coleta das cápsulas cefálicas, após a muda. A medida que completavam o ínstar desejado, as lagartas eram sacrificadas, fixadas e preservadas em fluido Dietrich.

As medidas de largura da cápsula cefálica foram tomadas sobre as lagartas fixadas, em vista frontal, sob uma lupa Spencer ${ }^{\circledR}$ equipada com escala micrométrica. Os dados relativos à largura da cápsula cefálica foram ajustados pelo método dos mínimos quadrados à forma logarítmica (linear) da função $y=a e^{b x}$ (SNEDECOR \& COCHRAN 1980).

As observações gerais foram feitas em um estereomicroscópio, após inclusão dos espécimes em gelatina glicerinada, para todos os estágios. As cápsulas cefálicas, utilizadas no estudo da quetotaxia primária, foram reidratadas e montadas entre lâmina/lamínula, utilizando-se o mesmo meio de inclusão. As observações ultraestruturais externas foram feitas através de microscopia eletrônica de varredura, onde o material foi previamente desidratado em ponto crítico (Bal-tec ${ }^{\circledR}-$ CPD 030), montado com fita dupla face sobre suporte metálico, metalizado com ouro em um metalizador Bal-tec ${ }^{\circledR}$ - SCD 050 e posteriormente visualizado e fotografado em um microscópio eletrônico de varredura JEOL ${ }^{\circledR}$ JSM-5800. Todas as ilustrações foram feitas com uma lupa Spencer ${ }^{\circledR}$, provida de uma grade micrométrica, exceto para as cápsulas cefálicas onde utilizou-se também um microscópio óptico Spencer ${ }^{\circledR}$. O padrão de coloração da larva de quinto ínstar e da pupa foi representado em aquarela com base em fotografias e na observação de espécimes in vivo. As ilustrações e 
análises microscópicas foram feitas baseadas na comparação de, no mínimo, cinco exemplares, exceto quando mencionado.

Para o estágio de ovo, adotou-se a nomenclatura proposta por BEEBE et al. (1960) para os caracteres gerais; HINTON (1981) e DowNEY \& ALLYN (1981) para os aspectos ultraestruturais. Para descrição da quetotaxia dos ínstares larvais baseou-se em FLEMING (1960) e STEHR (1987), o qual também foi utilizado para descrever o padrão dos ganchos dos larvópodos. Na caracterização do estágio de pupa seguiu-se MOSHER (1916).

\section{RESULTADOS E DISCUSSÃO}

\section{Ovo}

O ovo de D. juno juno apresenta coloração amarela, tornando-se vermelho escuro no final do desenvolvimento embrionário. Possui formato semi-esférico, com base plana e ápice côncavo (Fig. 1). As medidas (média \pm erro padrão), efetuadas para 10 espécimes, referentes ao diâmetro e à altura, foram respectivamente de $0,54 \pm 0,010$ e $0,90 \pm 0,003 \mathrm{~mm}$. Os valores encontrados são menores que os obtidos por BEEBE $e t$ al. (1960), evidenciando assim uma variação dentro da subespécie.

O cório apresenta-se ornamentado com carenas verticais (Vr, Fig. 1) e horizontais (Hr, Fig. 1), conforme já descrito por BEEBE et al. (1960). O número de carenas verticais varia de 13 a 15 e o de horizontais de 15 a 16, aproximando-se dos valores encontrados por BEEBE et al. (1960). No que se refere às carenas verticais, algumas são menores e não atingem o ápice do ovo (Fig. 1), característica também observada por MUYSHONDT et al. (1973) para D. juno huascuma. As intersecções entre carenas verticais e horizontais delimitam na metade inferior do ovo células retangulares (Lc, Fig. 3), que encontram-se uniformemente distribuídas e com ângulos internos arredondados. Na metade superior, além destas, existem células pentagonais (Uc, Fig. 2) relacionadas com as carenas verticais que não atingem o ápice.

A região micropilar (Fig. 4) situa-se na parte apical do ovo, conforme já descrito por HINTON (1981) para outros lepidópteros (discussão em ANTUNES et al. no prelo). Esta região se subdivide em duas porções, denominadas por DOWNEY e ALLYN (1981) como ânulo e roseta. O ânulo corresponde à porção externa da região micropilar, sendo constituído por células que variam de arredondadas à poligonais. Internamente ao ânulo, está a roseta onde as células variam de tetragonais à hexagonais. Estas convergem em espiral para o centro, onde localizam-se as micrópilas (Mp, Fig. 4).

As aerópilas apresentam-se como pequenos poros circulares (Ac, Fig. 5) sobre todas as carenas verticais, mais especificamente nas regiões onde estas se interseccionam com as carenas horizontais. O peritrema das aerópilas é pouco evidenciado (Fig. 5), como já observado para outras espécies de heliconíneos (ANTUNES et al. no prelo; KAMINSKI et al. 2002).

\section{Larvas}

No primeiro ínstar, D. juno juno apresenta coloração marrom clara, observando-se o conteúdo intestinal por transparência. A fronte encontra-se fusionada ao clípeo constituindo um frontoclípeo, com sutura frontoclipeal não evidente (STEHR 

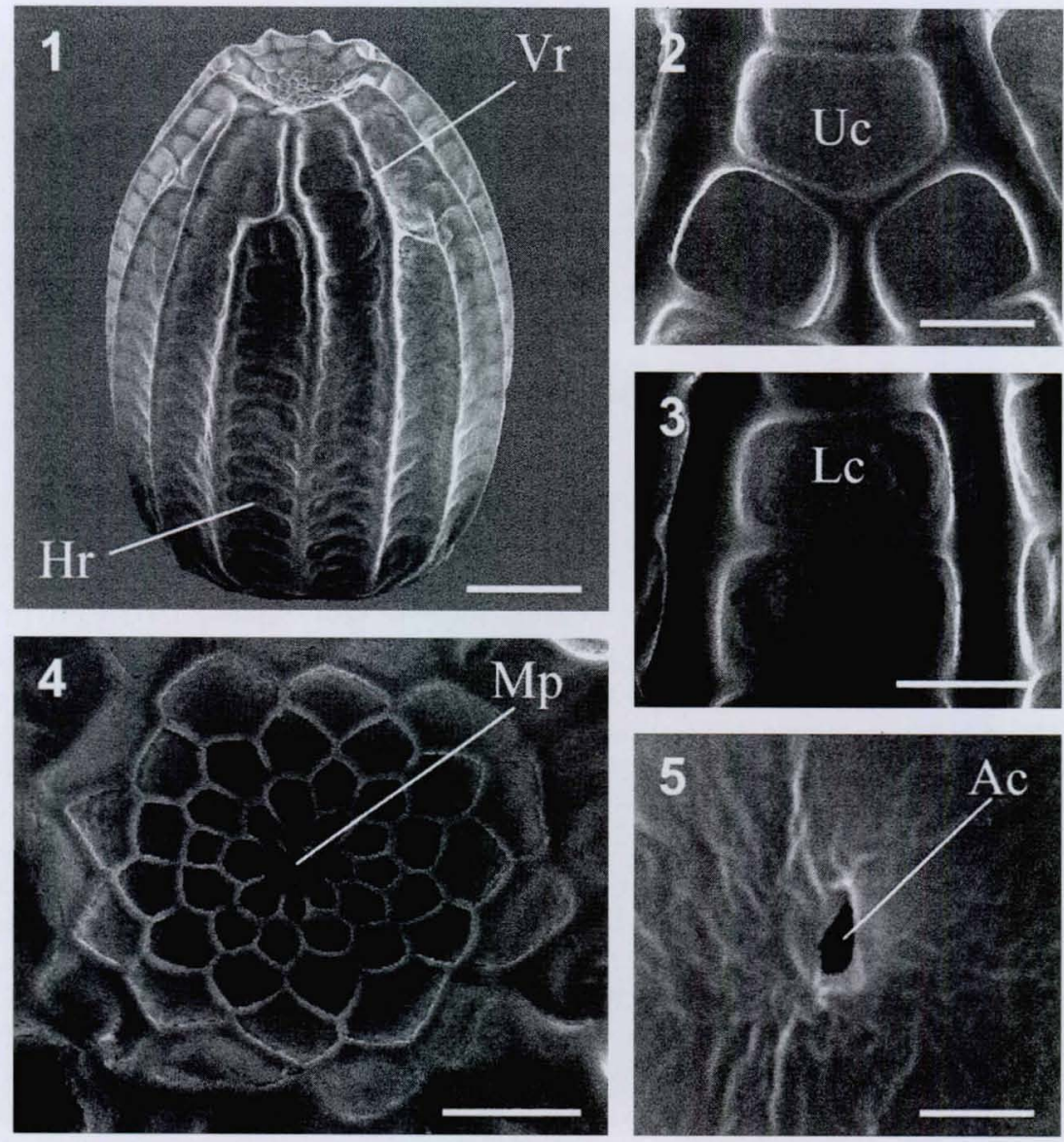

Figs 1-5. Ovo de Dione juno juno em microscopia eletrônica de varredura: (1) vista látero-dorsal; (2) células superiores; (3) células inferiores; (4) região micropilar; (5) aerópila. (Ac) Aerópila, (Hr) carena horizontal, (Lc) célula inferior, (Mp) micrópilas, (Uc) célula superior, (Vr) carena vertical. Barras $=200,50,50,50$ e $3 \mu \mathrm{m}$, respectivamente.

1987). As antenas encontram-se inseridas em uma área membranosa eversível, que em $D$. juno juno diferencia-se das outras espécies já estudadas Eueides isabella dianasa (ANTUNES et al. no prelo) e Heliconius erato phyllis (KAMINSKI et al. 2002), pois apresenta protuberâncias (Fig. 10).

Diversas cerdas encontram-se dispostas na cápsula cefálica (Fig. 6), cuja descrição se aproxima daquela apresentada de forma preliminar por FLEMING (1960). Em adição, além da cerda SS2 (Fig. 6) estão presentes na cápsula cefálica, porém não visíveis em vista frontal, as cerdas SS1 e SS3. A SS1 está localizada ventralmente ao estema 5 e anteriormente a cerda SS2. A SS3 situa-se abaixo do estema 6. Também, encontram-se evidentes, em vista dorsal, as microcerdas MD1, MD2 e MD3 (STEHR 1987), as quais não haviam sido detectadas por FLEMING 


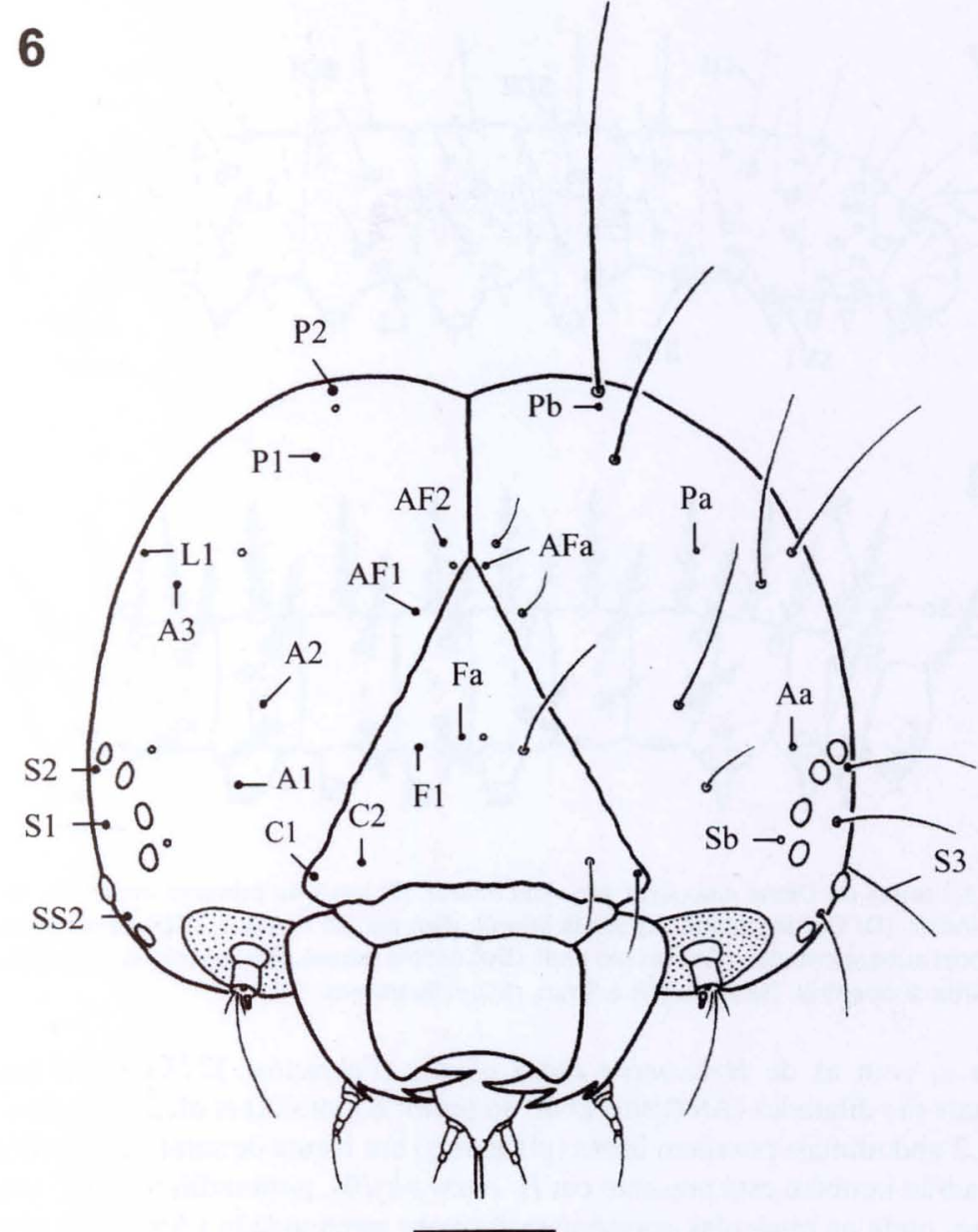

Fig. 6. Cápsula cefálica de larva de primeiro ínstar de Dione juno juno, em vista frontal. (A) Cerda anterior, (Aa) poro anterior, (AF) cerda adfrontal, (AFa) poro adfrontal, (C) cerda clipeal, (F) cerda frontal, (Fa) poro frontal, (L) cerda lateral, (P) cerda póstero-dorsal, (Pa e Pb) poros póstero-dorsais, (S) cerda estematal, (Sb) poro estematal, (SS) cerda subestematal. Barra = $10 \mu \mathrm{m}$.

(1960). Além do par de poros frontais (Fa, Fig. 6), já descrito por FLEMING (1960), registrou-se os poros MDa, La, Sa, SSa e MGa (StEHR 1987). Ao contrário dos demais, cuja disposição corresponde ao padrão de STEHR (1987), o poro MDa situa-se entre as microcerdas MD1 e MD2.

A quetotaxia do tórax e abdomên (Fig. 7) está de acordo com aquela proposta por FLEMING (1960). As cerdas localizadas dorsalmente são do tipo calaza (Fig. 11) e apresentam a porção terminal partida de 3 a 4 pontas (Fig. 12). Assim, contrastam com as de Eueides isabella dianasa (Hübner, 1806) que possuem porção terminal 

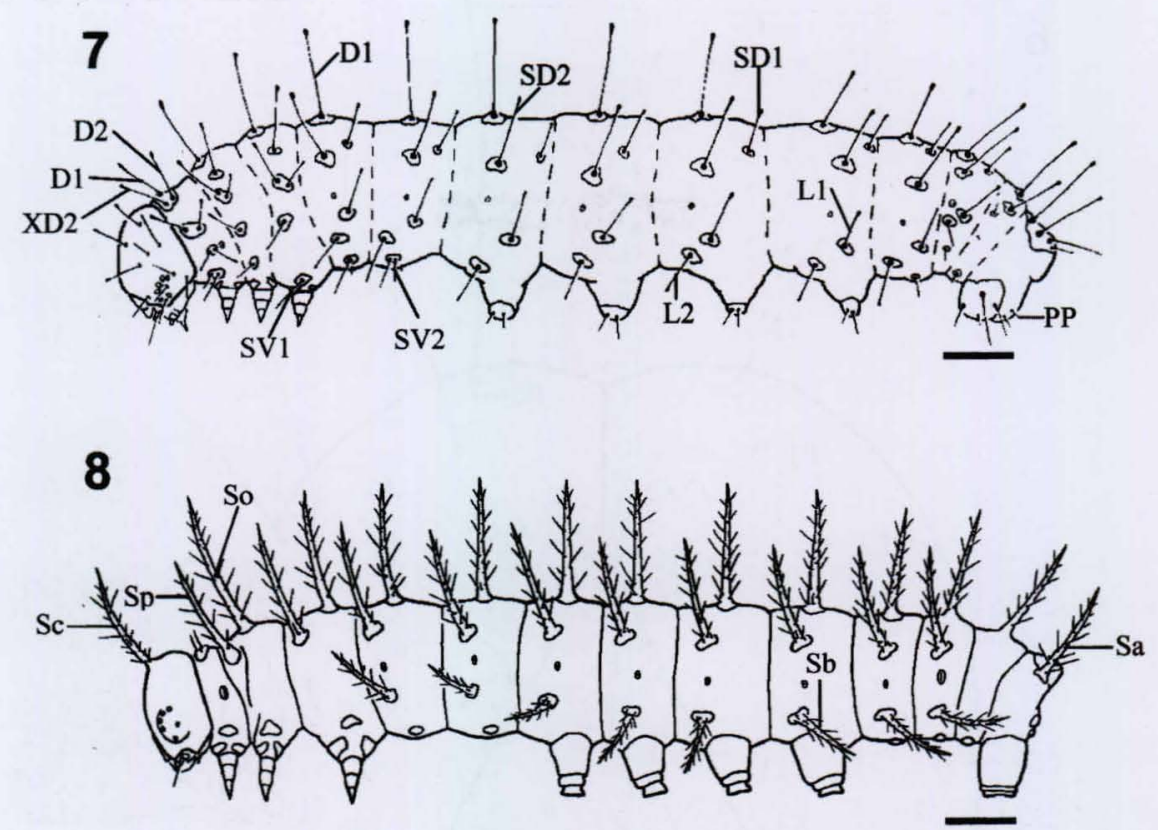

Figs 7-8. Larvas de Dione juno juno, em vista lateral: (7) larva de primeiro instar; (8) larva de quinto ínstar. (D) Cerda dorsal, (L) cerda lateral, (Sc) escolo cefálico, (SD) cerda subdorsal, (SI) escolo subespiracular, (Sn) escolo anal, (So) escolo dorsal, (Sp) escolo supraespiracular, (SV) cerda subventral. Barras $=0,3$ e $3 \mathrm{~mm}$, respectivamente.

afilada e, com as de Heliconius erato phyllis (Fabricius, 1775), cujas porções terminais são dilatadas (ANTUNES et al. no prelo; KAMINSKI et al. 2002). As cerdas L1 e L2 abdominais possuem bases (pináculas) em forma de semi-círculo (Fig. 7). Este padrão também está presente em $H$. erato phyllis, porém difere em $E$. isabella dianasa, onde as pináculas apresentam formato arredondado (ANTUNES et al. no prelo; KAMINSKI et al. 2002). Microtríquias (Fig. 15) estão presentes em grande quantidade, tanto látero quanto ventralmente, no tórax e abdômen.

Os espiráculos (Fig. 13) possuem formato circular e peritrema elevado, diferindo de $H$. erato phyllis, onde este é menos pronunciado e a abertura correspondente maior (KAMINSKI et al. 2002). Os espiráculos do protórax e do oitavo segmento abdominal seguem o padrão dos demais, porém são maiores.

Os ganchos dos larvópodos (Fig. 14) são uniordinais, unisseriais e apresentam-se distribuídos de forma circular na planta de cada larvópodo. A seção cilíndrica do larvópodo (SNODGRASS 1935) é incompleta, assim como em H. erato phyllis. Ventralmente, após o último par de ganchos, existem esclerotinizações cuticulares alargadas na base, denominadas placas anais, que teriam a função de expelir as pelotas fecais das larvas (SCOBLE 1992).

A partir do segundo ínstar, de D. juno juno, ocorrem significativas mudanças na coloração do tegumento, que torna-se marrom escura com manchas alaranjadas e 

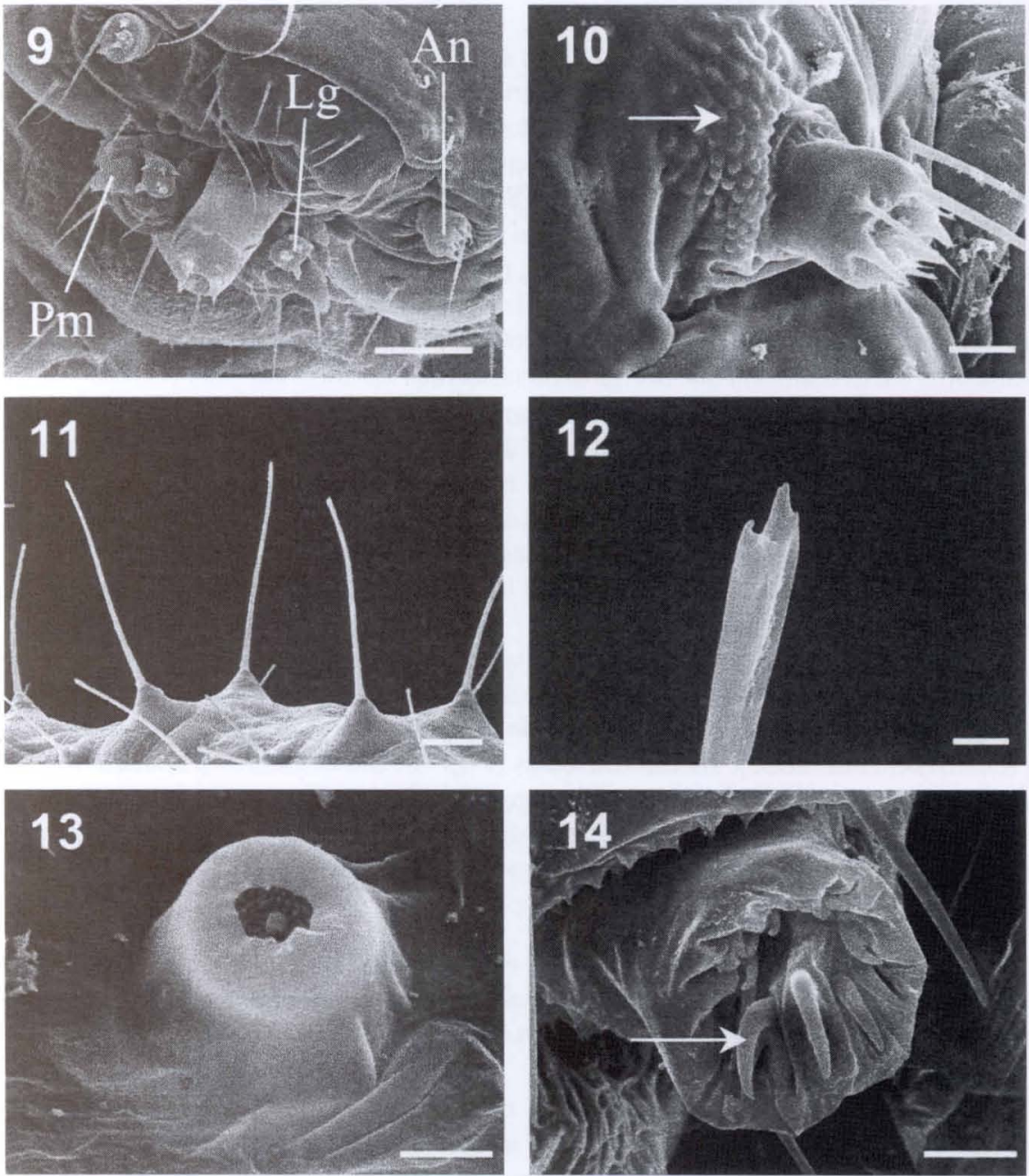

Figs 9-14. Larva de primeiro ínstar de Dione juno juno em microscopia eletrônica de varredura: (9) vista ântero-lateral da cápsula cefálica; (10) antena evidenciando-se protuberâncias (seta) da área membranosa eversível; (11) cerdas do tipo calaza em vista lateral; (12) porção apical de uma cerda em vista lateral; (13) espiráculo do segundo segmento abdominal; (14) planta de um larvópodo evidenciando os ganchos (seta). (An) Antena, (Lg) laciniogálea, (Pm) palpo maxilar. Barras $=50,10,50,5,5$ e $20 \mu \mathrm{m}$, respectivamente.

brancas, permanecendo dessa forma até o quinto ínstar (Fig. 41). A cápsula cefálica apresenta um par de escolos reduzidos. A placa protorácica apresenta um par de escolos, considerado uma provável sinapomorfia para o gênero Dione (PENZ 1999). As cerdas do protórax aparentemente seguem a quetotaxia descrita por FLEMING (1960) para o primeiro ínstar. O mesotórax e o metatórax apresentam a mesma disposição de cerdas, com a permanência de L1, SV1, SV2 e a adição de um escolo 
dorsal e um supraespiracular (PETERSON 1962). Do primeiro ao oitavo segmentos abdominais ocorre a adição de mais um escolo em relação ao tórax; assim os segmentos abdominais se constituem de um escolo dorsal, um supraespiracular e um subespiracular (Fig. 8). Nestes segmentos, permanecem apenas as cerdas subventrais da quetotaxia primária, representadas por SV1 no primeiro, segundo, sétimo e oitavo segmentos e, por SV1 e SV2, do terceiro ao sexto. O nono segmento abdominal possui apenas um escolo, localizado dorsalmente, permanecendo nele as cerdas primárias L1 e subventrais. O décimo segmento também possui apenas um escolo dorsalmente, denominado escolo anal (BEEBE et al. 1960). Dorsalmente, neste segmento, situa-se uma área esclerotinizada que abriga diversas cerdas secundárias.

No quinto ínstar, todas as estruturas atingem seu maior desenvolvimento permitindo assim uma melhor avaliação de seus caracteres. A coloração predominante é marrom escura entremeada por manchas alaranjadas, as quais situam-se aproximadamente alinhadas ao longo das áreas lateral e dorsal do corpo. Em adição, estão presentes pequenas manchas brancas em quase todo tegumento. Predomina o preto na cabeça, nos escolos, nas pernas torácicas e nos larvópodos, com exceção da planta que é bege (Fig. 41).

Os escolos (Fig. 17) de D. juno juno apresentam a porção terminal diferenciada em forma de cerda (Fig. 18), assim diferem daqueles de H. erato phyllis, cuja porção terminal é um prolongamento do próprio escolo sem constrição na base (KAMINSKI et al. 2002). As microtríquias (Fig. 16) são evidentes e abundantes, no quinto ínstar, distribuindo-se por todo tegumento larval. Os espiráculos apresentam formato elíptico (Fig. 19), diferenciando-se do primeiro ínstar, onde são arredondados. Os ganchos dos larvópodos tornam-se unisseriais e triordinais (Fig. 20).

\section{Identificação dos ínstares}

Ao contrário do verificado em H. erato phyllis (KAMINSKI et al. 2002), não encontram-se variações conspícuas na coloração entre os ínstares de $D$. juno juno que permitam a identificação destes com precisão, principalmente em relação aos intermediários.

As medidas de tendência central e de dispersão para a largura da cápsula cefálica dos ínstares larvais encontram-se na tabela I. Para os dados correspondentes, obteve-se a seguinte equação de crescimento: $\ln y=0,448 x-1,054 ; n=100 ; r=0,997$; $\mathrm{p}=0,0001$. Dessa forma, os dados se ajustaram a uma equação exponencial. Em média, a razão de crescimento entre os ínstares foi de 1,56. Não houve sobreposição da largura da cápsula cefálica entre os ínstares (Tab. I). Assim, o padrão de crescimento da cápsula cefálica de $D$. juno juno segue a Regra de Brooks-Dyar, o que permite a identificação de seus ínstares larvais, conforme observado para diversos lepidópteros (DALY 1985). Resultados semelhantes foram obtidos para $E$. isabella dianasa e $H$. erato phyllis (ANTUNES et al. no prelo; KAMINSKI et al. 2002).

\section{Pupa}

A pupa apresenta coloração não uniforme constituindo-se numa mistura de diversas tonalidades de marrom, bege e cinza, entremeadas por regiões esbranquiçadas e escuras. (Fig. 42). Há variações quanto à intensidade de escurecimento do tegumento, dependendo do indivíduo em questão e do período de desenvolvimento pupal. 

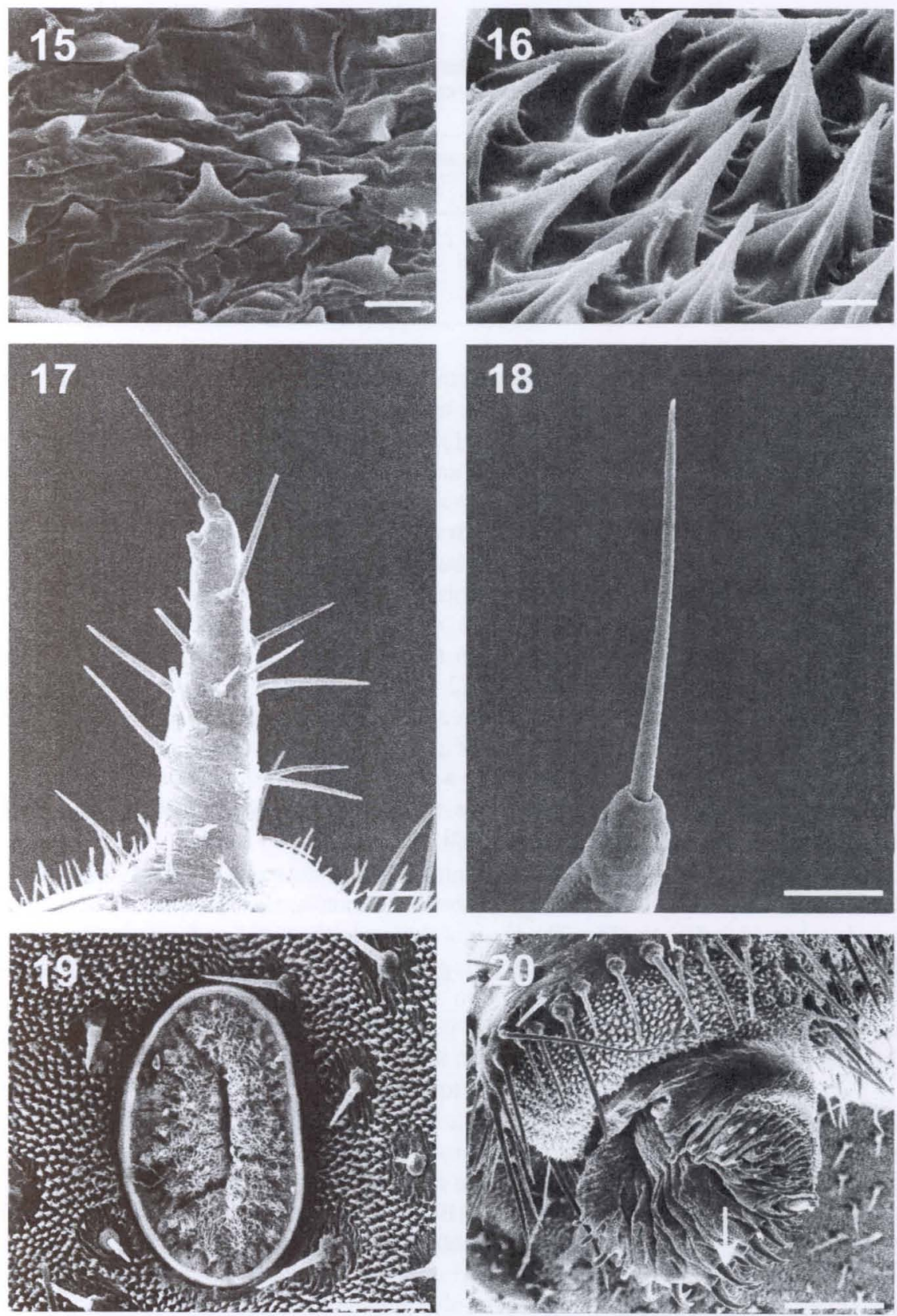

Figs 15-20. Larva de Dione juno juno em microscopia eletrônica de varredura: (15) microtriquias de larva de primeiro instar; (16) microtriquias de larva de quinto instar; (17) escolo de larva de quinto ínstar; (18) porção terminal de um escolo de larva de quinto ínstar; (19) espiráculo abdominal de larva de quinto ínstar; (20) planta de um larvópodo de larva de quinto ínstar evidenciando ganchos (seta). Barras $=5,5,200,100,150$ e $450 \mu \mathrm{m}$, respectivamente. 
Tabela I. Média aritmética e erro padrão, intervalo de variação e razão de crescimento da largura da cápsula cefálica dentre os ínstares larvais de Dione juno juno, criados sobre Passiflora edulis. $\mathrm{n}=20$ /ínstar.

\begin{tabular}{cccc}
\hline \multirow{2}{*}{ Instar } & \multicolumn{3}{c}{ Largura da cápsula cefálica $(\mathrm{mm})$} \\
\cline { 2 - 4 } & Média \pm erro padrão & Intervalo de variação & Razão de crescimento \\
\hline I & $0,53 \pm 0,003$ & $0,52-0,54$ & - \\
II & $0,86 \pm 0,003$ & $0,85-0,88$ & 1,62 \\
III & $1,37 \pm 0,011$ & $1,30-1,41$ & 1,59 \\
IV & $2,19 \pm 0,013$ & $2,08-2,29$ & 1,60 \\
V & $3,13 \pm 0,035$ & $3,02-3,43$ & 1,43 \\
\hline
\end{tabular}

Seguindo o padrão geral para Nymphalidae (MOSHER 1916), D. juno juno não apresenta sutura epicranial e possui as pernas pro- e mesotorácias estendidas antero-ventralmente até os olhos (Fig. 21). Estes, de acordo com o verificado para Lepidoptera (MOSHER 1916), se constituem de duas regiões distintas: a primeira (Gr, Fig. 24), uma estreita faixa com aspecto reluzente; a segunda (Sr, Fig. 24), que é circundada pela primeira diferencia-se desta pela presença de rugosidades e cerdas. Ventralmente, visualizam-se as mandíbulas (Md, Figs 21,23), em posição mediana, e assim como na maioria dos Lepidoptera, não são funcionais. Entre as duas mandíbulas situa-se o labro (Lb, Fig. 23). Acima do labro encontra-se o clípeo ( $\mathbf{C l}$, Fig. 23). As maxilas (Mx, Fig. 21) situam-se abaixo do labro e das mandíbulas. Um par de projeções curtas (Cp, Figs 21, 22, 25), em forma de concha, e achatadas dorso-ventralmente, estão presentes na cabeça. As projeções possuem superfície corrugada e repleta de protuberâncias (Fig. 26). As antenas (An, Fig. 21) encontram-se, em vista ventral, acompanhando a margem externa das asas mesotorácicas. Possuem tubérculos em seus segmentos (Fig. 27), os quais apresentam aspecto multilobado (Fig. 28), na porção proximal.

O tórax divide-se em três segmentos de formato e tamanho distintos, conforme descrito por BEEBE et al. (1960) para os heliconíneos. O primeiro, possui um par de tubérculos dorsais (Fig. 22). O segundo segmento torácico é o maior dos três, possuindo dois pares de tubérculos e, na região mediana dorsal uma crista de aspecto corrugado (Br, Figs 22, 29). O terceiro segmento torácico é o menor dos três, também possuindo um par de tubérculos dorsais. As pernas protorácicas (Le1, Fig. 21) são curtas, equivalendo a cerca de um terço do comprimento das asas (MOSHER 1916) e possuem dois pares de pequenos tubérculos. As pernas mesotorácicas (Le2, Fig. 21) encontram-se entre as protorácicas e as antenas, possuindo três pares de tubérculos, sendo os dois primeiros visíveis em microscopia óptica (Figs 21, 30). As pernas metatorácicas estão totalmente encobertas pelas asas anteriores. Na base da asa anterior, existem dois tubérculos (Bt, Fig. 31) e uma crista longitudinal (BI, Fig. 31), que segundo BEEBE et al. (1960) estão sempre presentes na subfamília Heliconiinae. Na asa existem três tubérculos submarginais (St, Figs 21, 22, 32) próximos ao terceiro e quarto segmentos abdominais e três tubérculos pós medianos (Pt, Fig. 32) mais afastados da margem externa da asa.

Segundo Mosher (1916), os tubérculos encontram-se dispostos em sete linhas para Nymphalidae, concentrando-se no dorso do abdômen. D. juno juno segue este padrão, possuindo cinco linhas de tubérculos visíveis em vista dorsal e duas em vista 
21

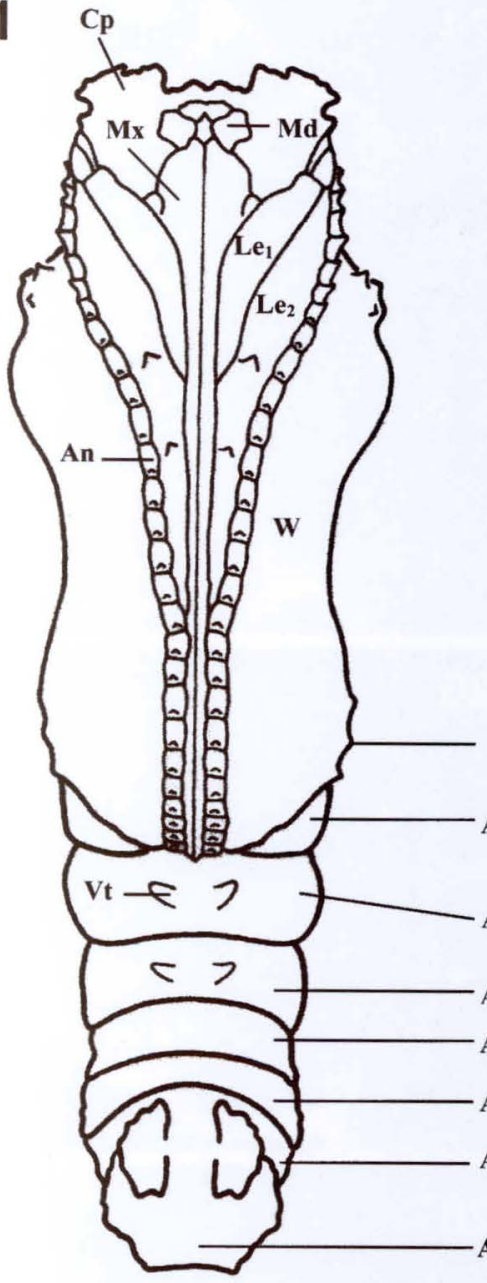

22

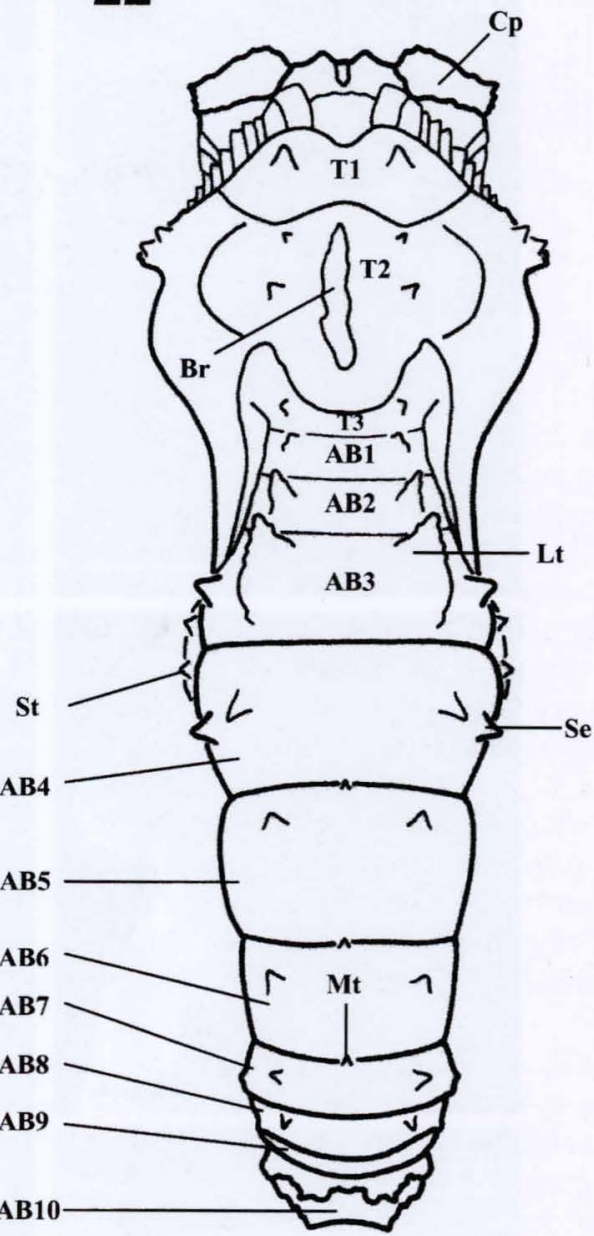

Figs 21-22. Pupa de Dione juno Juno: (21) vista ventral; (22) vista dorsal. (AB) Segmento abdominal, (An) antena, (Br) crista médio-dorsal, (Cp) projeção cefálica, (Le 1 ) perna protorácica, (Le2) perna mesotorácica, (Lt) tubérculo lateral, (Md) mandíbula, (Mt) tubérculo médiodorsal, (Mx) maxila, (Se) tubérculo supraespiracular, (St) tubérculo submarginal, (T) segmento torácico, $(\mathbf{V t})$ tubérculo ventral, $(\mathbf{W})$ asa. Barra $=2 \mathrm{~mm}$.

ventral. As cinco linhas dorsais se constituem de uma médio-dorsal, um par de linhas látero-dorsais e um par de linhas supraespiraculares. O par de linhas látero-dorsais se estende desde o primeiro segmento torácico até o oitavo segmento abdominal. No terceiro e quarto segmentos abdominais, os tubérculos são mais evidentes (Fig. 35), porém não apresentam projeções espinhosas, como em $H$. erato phyllis (KAMINSKI et al. 2002). O par de linhas supraespiraculares aparece apenas no terceiro e quarto 

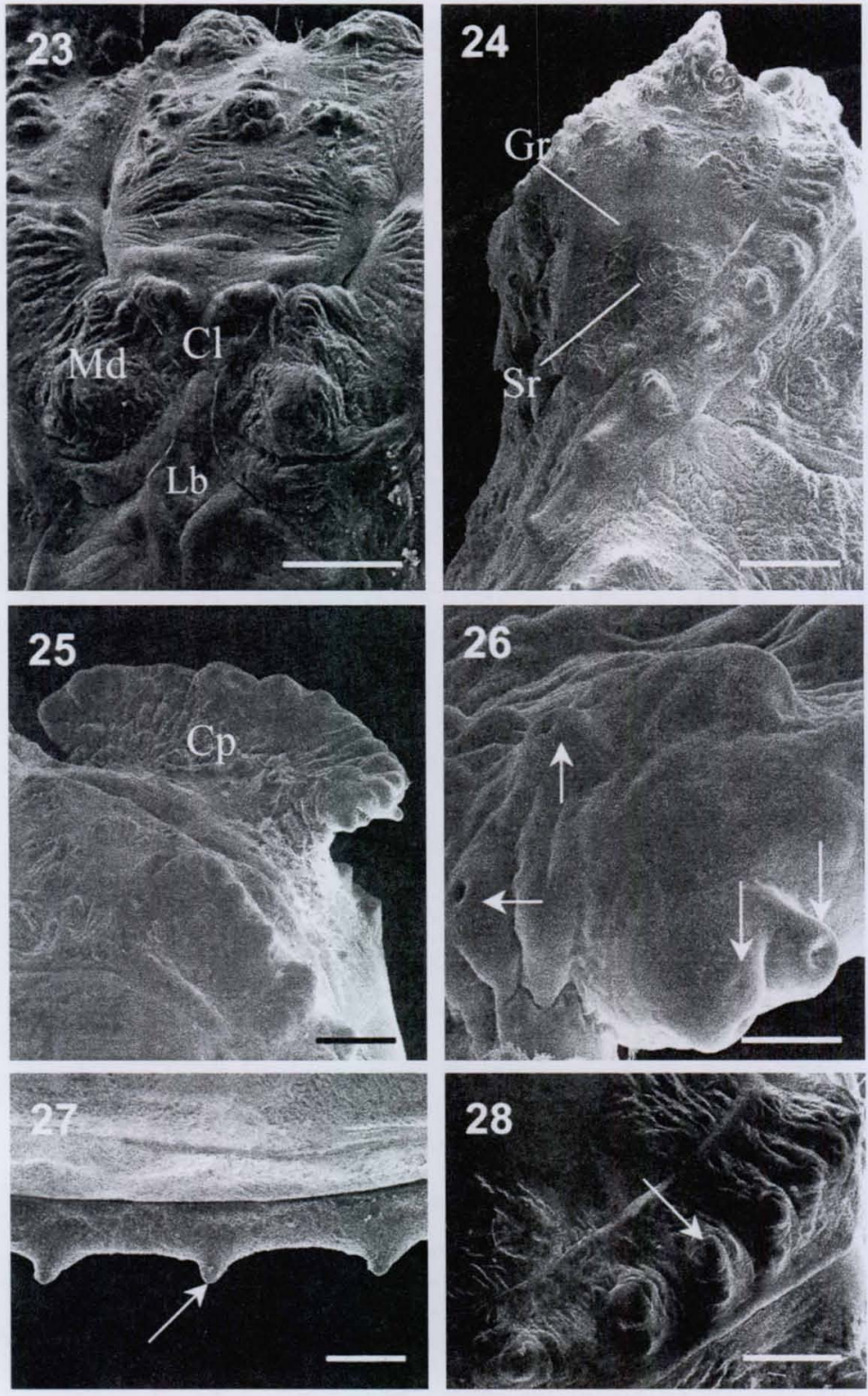

Figs. 23-28. Pupa de Dione juno juno em microscopia eletrônica de varredura: (23) cabeça em vista ventral; (24) cabeça em vista lateral; (25) projeção cefálica em vista dorsal; (26) detalhe da projeção cefálica, evidenciando protuberâncias (setas); (27) porção distal da antena em vista lateral, evidenciando tubérculos (seta); (28) porção proximal da antena, evidenciando tubérculos multilobados (seta). Cl) Clípeo, (Cp) projeção cefálica, (Gr) faixa de aspecto reluzente do olho, (Lb) labro, (Md) mandibula, (Sr) porção esculturada do olho. Barras $=500$, $500,200,50,200$ e $200 \mu \mathrm{m}$, respectivamente. 

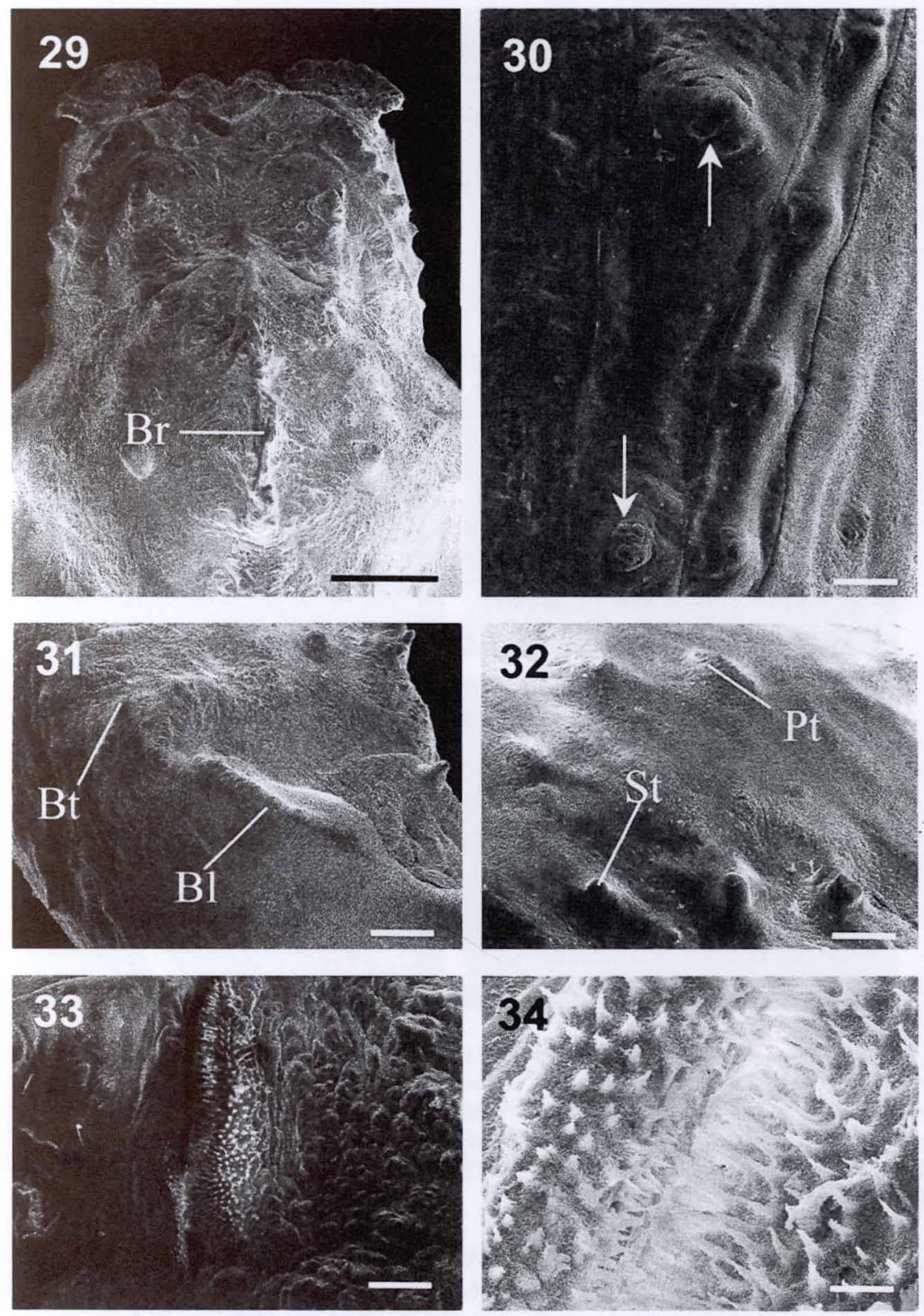

Figs 29-34. Pupa de Dione juno juno em microscopia eletrônica de varredurra: (29) cabeça, primeiro e segundo segmentos torácicos, em vista dorsal; (30) tubérculos da perna mesotorácica (setas); (31) vista lateral da porção proximal da asa anterior; (32) vista lateral da asa; (33) espiráculo mesotorácico; (34) detalhe da abertura do espiráculo mesotorácico. (BI) Crista longitudinal, (Br) crista médio-dorsal, (Bt) tubérculo basilar, (Pt) tubérculo pós-mediano, (St) tubérculo submarginal. Barras $=1 ; 0,2 ; 0,5 ; 0,2 ; 0,1 \mathrm{~mm}$ e $20 \mu \mathrm{m}$, respectivamente. 

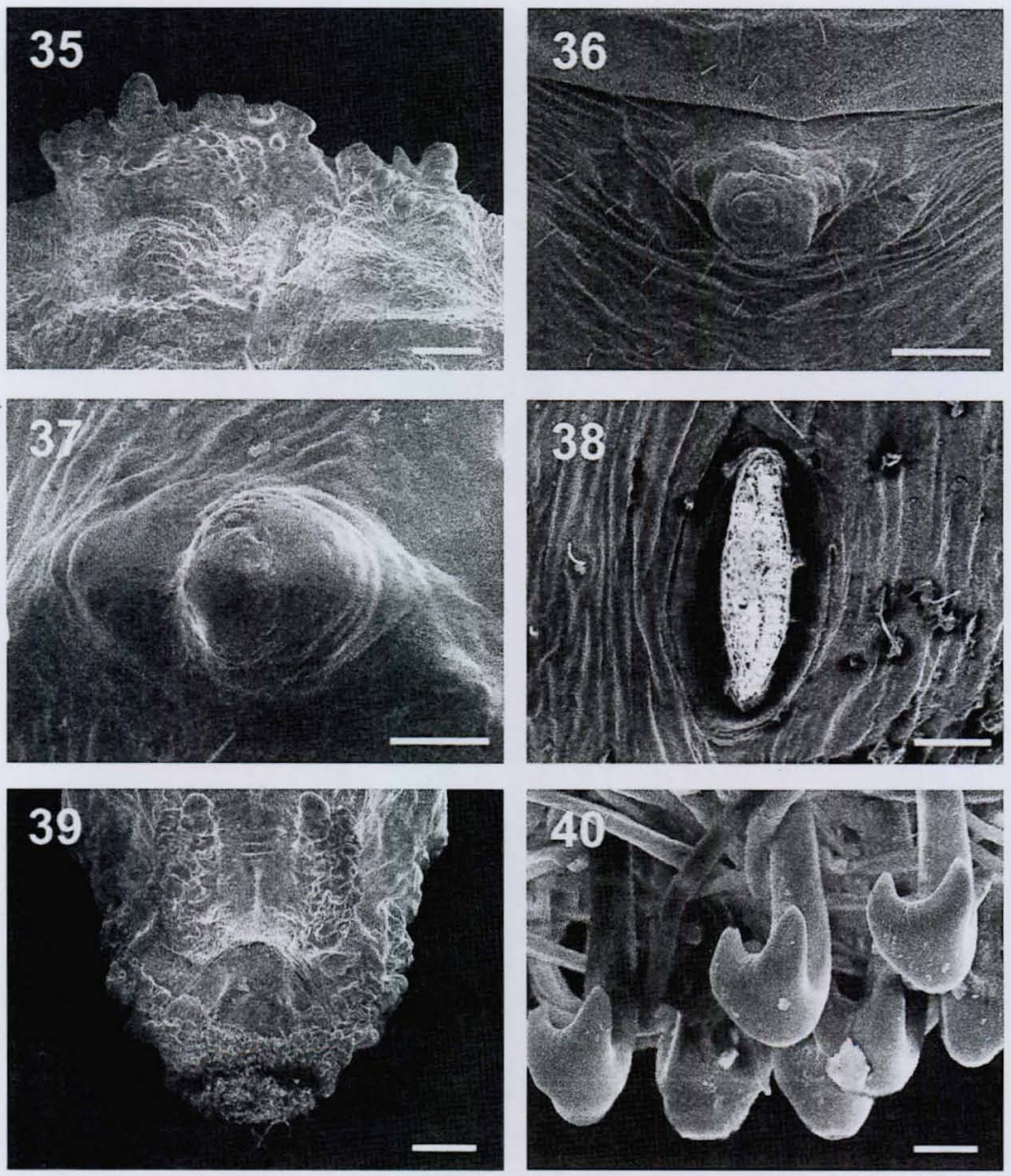

Figs 35-40. Pupa de Dione juno juno em microscopia eletrônica de varredura: (35) tubérculos laterais do terceiro e quarto segmentos abdominais, em vista lateral; (36) tubérculo médiodorsal do sexto segmento abdominal, em vista dorsal; (37) tubérculo supraespiracular do quarto segmento abdominal, em vista látero-dorsal; (38) espiráculo do quarto segmento abdominal; (39) cremáster, em vista ventral; (40) ganchos do cremáster. Barras $=500,250$, $100,100,500$ e $20 \mu \mathrm{m}$, respectivamente.

segmentos abdominais (Se, Figs 22, 37). A linha médio-dorsal se restringe ao quinto, sexto e sétimo segmentos (Mt, Figs 22, 36). As duas linhas ventrais se encontram no quinto e sexto segmentos abdominais, em posição mediana (Vt, Fig. 21).

O espiráculo mesotorácico localiza-se em um sulco na junção entre os segmentos pro- e mesotorácicos (Figs 33 e 34). Os demais espiráculos localizam-se do primeiro ao oitavo segmentos abdominais e possuem formato elíptico (Fig. 38), com exceção do oitavo, que é vestigial, não apresentando abertura distinta. O espiráculo do primeiro segmento abdominal encontra-se encoberto pelas asas. 
O cremáster (Fig. 39) é truncado posteriormente, apresentando formato sub-quadrangular à semelhança de A. vanillae (BEEBE et al. 1960). Possui em sua região terminal grande número de cerdas e ganchos. Estes possuem a extremidade recurvada e subdividida em duas pontas (Fig. 40), como em E. isabella dianasa e H. erato phyllis (ANTUNES et al. no prelo; KAMINSKI et al. 2002).

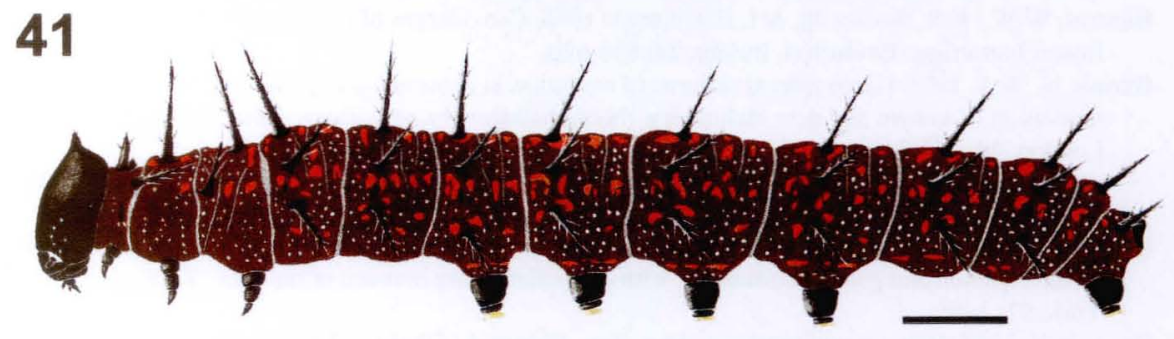

42

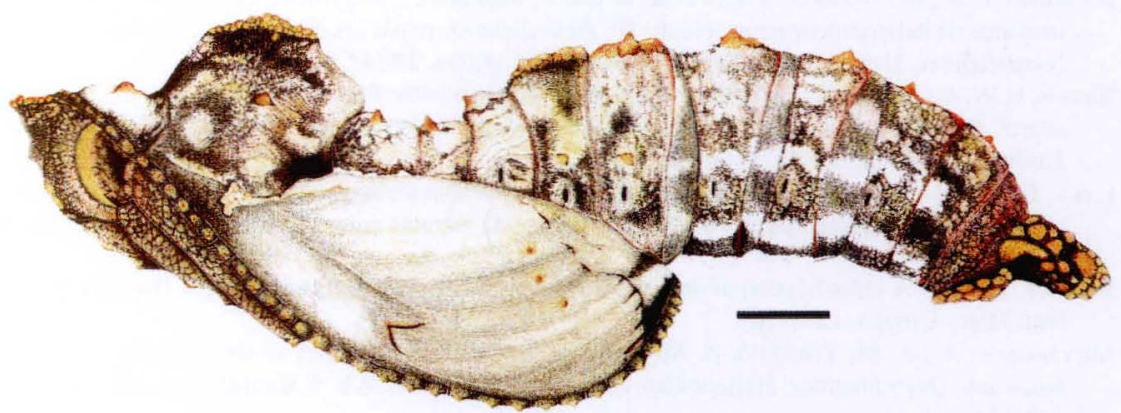

Figs 41- 42. Padrão de coloração da larva (41), ao início do quinto instar, e pupa (42) de Dione juno juno. Barras $=3$ e $2 \mathrm{~mm}$, respectivamente.

AGRADECIMENTOS. Os autores agradecem ao Centro de Microscopia Eletrônica da UFRGS, em especial à Christiane Lopes, Francis Farret Darsie e Miriam Souza dos Santos pelo auxílio prestado na preparação das amostras e realização das fotos. Da mesma forma, à Mônica Fagundes Acioli e Vidica Bianch pelo auxílio na criação dos insetos e preparação do material para a microscopia. Agradecemos especialmente ao Marcelo Duarte (UFPR) e a um revisor anônimo, pelas valiosas críticas e sugestões efetuadas na versão final do manuscrito. Parte dos custos deste estudo foi mantido pela FAPERGS, Projeto $n^{\circ}$ 94/50941.7, concedido a Gilson R.P. Moreira. 


\section{REFERÊNCIAS BIBLIOGRÁFICAS}

Antunes, F.F.; A.O. Menezes JR.; M. TAvares \& G.R.P. Moreira (no prelo). Morfologia externa dos estágios imaturos de heliconíneos neotropicais: I. Eueides isabella dianasa (Hübner, 1806). Revta bras. Ent., Curitiba.

Beebe, C.W.; J. Crane \& H. Fleming. 1960. A comparison of eggs, larvae and pupae in fourteen species of heliconiine butterflies from Trinidad, W.I. Zoologica, New York, 45: 111-154.

BENSON, W.W.; K.S. BRown JR. \& L.E. GILBERT. 1976. Coevolution of plants and herbivores: passion flower butterflies. Evolution, Bolder, 29: 659-680.

BRown JR., K.S. 1975. Geographical patterns of evolution in neotropical Lepidoptera. Systematics and derivation of known and new Heliconiini (Nymphalidae: Nymphalinae). Jour. Entomol., ser. B, London, 44: 201-242.

. 1981. The biology of Heliconius and related genera. Ann. Rev. Entomol., Stanford, 26: 427-456.

BRown JR., K.S \& O.H.H. MielKe. 1972. The heliconians of Brazil (Lepidoptera: Nymphalidae). Part II. Introduction and general comments, with a supplementary revision of the tribe. Zoologica, New York, 57: 1-40.

Daly, H.V. 1985. Insect morphometrics. Ann. Rev. Entomol., Stanford, 30: 415-438.

DEVRIES, P.J. 1987. The butterflies of Costa Rica and their natural history: Papilionidae, Pieridae, Nymphalidae. Princeton, Princeton Univ., XXII+327p.

Downey, J.C \& A.C. AlLYN JR. 1981. Chorionic sculpturing in eggs of Lycaenidae. Part I. Bull. Allyn Mus., Gainesville, 61: 1-29.

EMSLEY, M.G. 1963. A morphological study of imagine Heliconiinae (Lepidoptera: Nymphalidae) with a consideration of the evolutionary relationships within the group. Zoologica, New York, 48: 85-130.

FLEMING, H. 1960. The first instar larvae of the Heliconiinae (Butterflies) of Trinidad, W.I. Zoologica, New York, 45: 91-110.

Hinton, H.E. 1981. Biology of insect eggs. London, Pergamon, Vol. 1, XXIII+473p.

KAMINSKI, L.A.; M. TAVARES; V.G. FerRo \& G.R.P. Moreira. 2002. Morfologia externa dos estágios imaturos de heliconíneos neotropicais: III. Heliconius erato phyllis (Fabricius, 1775) (Lepidoptera, Nymphalidae, Heliconiinae). Revta bras. Zool., Curitiba, 19 (4): 977-993.

KRENN, H.W. \& C.M. PENZ. 1998. Mouthparts of Heliconius butterflies (Lepidoptera: Nymphalidae): A search for anatomical adaptations to pollen-feeding behavior. Int. Jour. Insect Morphol. \& Embryol., Kidlington, 27: 301-309.

LaRA, F.M.; A.L. Boiça JR.; J.C. Barbosa. 1999. Preferência alimentar de Dione juno juno (Cramer) por genótipos de maracujazeiro e avaliação do uso de extratos aquosos. Sci. Agric., Piracicaba, 56: 665-671.

Mosher, E. 1916. A classification of the Lepidoptera based on characters of the pupa. Bull. Ill. St. Lab. Nat. Hist., Urbana, 12: 1-165.

MuYshondt, A.; A. M. Young \& A. MUYshondT JR. 1973. The biology of the butterfly Dione juno huascama (Nymphalidae: Heliconiinae) in El Salvador. Jour. N.Y. Entomol. Soc., New York, 81: 137-151

PENZ, C.M. 1999. Higher level phylogeny for the passion-vine butterflies (Nymphalidae, Heliconiinae) based on early stage and adult morphology. Zool. Jour. Linn. Soc., London, 127: 277-344.

PETERSON, A. 1962. Larvae of insects. An introduction to Neartic species. Part I. Lepidoptera and plant infesting Hymenoptera. Michigan, Edwards Brothers Inc., 315p.

SCOBLE, M.J. 1992. The Lepidoptera: form, function, and diversity. Oxford, Oxford University Press, $\mathrm{XI}+404 \mathrm{p}$.

SNEDECOR, G.W. \& W.G. Cochran. 1980. Statistical methods. Ames, Iowa State Univ. Press, $7^{\text {th }}$ ed., $507 \mathrm{p}$.

SNODGRASS, R.E. 1935. Principles of insect morphology. New York, McGraw-Hill, 667p.

STEHR, F.W. 1987. Order Lepidoptera, p. 288-305. In: F.W. STEHR (Ed.). Immature insects. Dubuque, Kendall/Hunt, Vol. 1, XII+754p.

VANDERPLANK, J. 1991. Passion flowers and passion fruit. Cambridge, MIT, 176p.

Recebido em 02.1.2002; aceito em 11.IX.2002

Revta bras. Zool. 19 (4): 961 - 976, 2002 